\title{
Radiation Oncology
}

National Cancer Institute

\section{Source}

National Cancer Institute. Radiation Oncology. NCI Thesaurus. Code C17760.

The study of the effects of ionizing radiation for treatment of tumors. 